\title{
Characterization and Morphological Properties of Glass Fiber Reinforced Epoxy Composites Fabricated Under Varying Degrees of Hand Lay-Up Techniques
}

\author{
*1'ADEKOMAYA, O; ${ }^{2}$ ADEDIRAN, AA; ${ }^{3}$ ADAMA, K \\ ${ }^{1}$ Department of Mechanical Engineering, Faculty of Engineering, College of Engineering and Environmental Studies, Olabisi Onabanjo \\ University, Ibogun Campus, Ifo, Ogun State, Nigeria. \\ ${ }^{2}$ Department of Mechanical Engineering, College of Science and Engineering, Landmark University, P.M.B 1001, Omu-Aran, Kwara State, \\ Nigeria. \\ ${ }^{3}$ Department of Agricultural Engineering, Faculty of Engineering, College of Engineering and Environmental Studies, Olabisi Onabanjo \\ University, Ibogun Campus, Ifo, Ogun State, Nigeria. \\ *Corresponding author Email: oludaisiyetunde@gmail.com, adekomaya.oludaisi@oouagoiwoye.edu.ng) \\ (Corresponding author contact Tel.no $+2348034410652,+2348059396975)$
}

\begin{abstract}
In this paper, attempts were made to study the progression of fibre-matrix adhesion of five composite specimens taking into consideration the hand lay-up method of composite formation. The ampreg 21 epoxy resin was used as the matrix for the glass fibre-epoxy resin formation. E- Glass fibre was used as matrix reinforcement. The morphology and the XRD of these composites were examined. Key of the findings from the morphological analysis of these composites showed that the fractured surface of the samples depicted better adhesion between the matrix and the fibres. The micrographs and EDS of the composite specimens also showed the retention of elemental composition of the glass fibre which is in line with other published works. The XRD results of these composites indicated a peak at Bragg's angle $2 \theta=20.6^{\circ}$, affirming the remnant crystalline silica in the composite. Hence, these composites are projected to possess better dimensional stability adaptable for high performance structural applications.
\end{abstract}

DOI: https://dx.doi.org/10.4314/jasem.v22i1.20

Copyright: Copyright (c) 2017 Adekomaya et al. This is an open access article distributed under the Creative Commons Attribution License (CCL), which permits unrestricted use, distribution, and reproduction in any medium, provided the original work is properly cited

Dates: Received 17 November 2017; Received in revised form 16 January 2018; Accepted 16 January 2018

Keywords: composite, interfacial adhesion, morphology, reinforcing fibre.

\section{INTRODUCTION}

Thermosetting based matrix in the likes of epoxy resins have been used for many applications such as reinforcement of composites, coatings of materials, and other engineering formations. These materials are known to provide flexible design application with high durability, coupled with their weight reduction properties. However, their inherent brittleness in many experimental works restrains many of its applications (Dong et al. 2014). Researchers (Abdellaoui et al. 2015) have reported on toughening of epoxy reinforced composite with much emphasis on its salient properties. Thus, the incorporation of additional rubbery phase into the composite tend to separate matrix during cure leading to different morphologies (Zhao et al. 2015). Findings from Natarajan and Balasubramanya (2014) showed that toughness value of composite was enhanced when rubber was added to the matrix at the expense of modulus and thermal stability of the material. However, authors (Thomason and Yang 2014) have suggested the incorporation of thermoplastic as only sustainable means of enhancing the structural properties of thermosetting composites. Although, a divergent view was observed in a thermoplastic epoxies composite by (Devaux and Caze 2000), with a tendency of exhibiting various types of morphology, resulting into complex backbone structure, and different molecular weight which complicates the analysis of such composite. The behavior of an epoxy matrix composites with unsaturated polyester and polyurethane matrix have been studied by (Rahman et al. 2013). They found that these specimens displayed good interfacial adhesion between the fiber and the resin resulting in better mechanical properties. However, some other authors (Etcheverry and Barbosa 2012) have suggested better approach of improving the morphological properties of polymer composite through fiber surface modifications and the formation of functionalities by plasma treatment. This poor adhesion between fibers and most matrices are often characterized by low off-axis properties. This limitation may further aggravate the skin-core morphology in most polymer materials thereby resulting in the weaker skin properties of evolving composite. Allred et al. (2003) suggested a novel method by incorporating amine groups into the surface of fiber thereby exposing them to plasmas treatment. This approach was later flawed following the formation of strong covalent bonds at the composite interface (Miller et al. 2010).

Interfacial adhesion between reinforcing fibers and matrices can be enhanced by various methods. As recommended in recent published work by Biswas et 
al. (2011), the most effective strategy is tailoring the fiber in hierarchical method by means of sizing the fiber along a specific orientation. The samples developed in this manner tend to withstand erosion/wear as revealed by most characterization and morphological tests. Part of the findings reported in most works showed an improved bonding between the glass fiber and the resin matrix when the oriented reinforced composite materials were developed in the formation of fiber and the epoxy resin. In a similar manner, Kenane, Benmedakhene, and Azari (2010) reported $30 \%$ wear/erosion reduction in characterised fibre reinforced composite despite the treatment of glass fiber. The key findings published by Norman and Robertson (2003) in their work showed that fibres which align perpendicularly within the fracture plane tend to result in uniform interfacial bonding. But, some other researchers who worked on the oriented reinforced fibers at oblique angles at the same operating conditions have faulted this conclusion. This include the work of Fara and Pavan (2004) who studied the dispersion of nylon with uniformly aligned fibers over a selected range of angles. Their morphological results showed that fracture occurred along the direction of fiber orientation in most cases while fiber at perpendicular plane were more resilient to fracture. It is therefore necessary to carry out incremental work with a view of establishing the morphology and orientation of the interfacial bonding between glass fiber reinforced epoxy under varying degrees of hand lay-up techniques.

\section{MATERIAL AND METHODOLOGY}

All materials used in this experimental work were sourced commercially from AMT composite in Johannesburg and were used as received. The epoxy resin used in this work was Ampreg 21 resin and key of the properties of this newly developed resin is its adaptability in hand lay-up manufacturing of composite. The E-glass fiber [bi-woven, $360 \mathrm{gsm}$ ] was commercially obtained from the same company and manufacturing of the composites were carried out in five phases taking into consideration fibre loading and orientation in the development of these composites. In the course of this experimental work, five composite materials were fabricated and were denoted by the percentage of fibre contents in the composite. Also, the orientation of this fibre in the resin were also studied morphologically to predict the interfacial adhesion of this type of composite viz-a-viz the unoriented composites.

The tensile fractured parts of each of the five composite materials (glass fiber reinforced epoxy) were studied using a scanning electron microscope (FESEM, JoelTM, model JSM-7600F) in order to ascertain the interfacial adhesion of all the specimens fabricated. A voltage of $16 \mathrm{kV}$ and existing working space between 4-6 mm was used during the morphological analysis.

The degree of dispersion of reinforcing fibre in the resin was studied using $\mathrm{x}$-ray diffraction analyses (XRD). The XRD patterns of the five composite specimen each representing composite panel fabricated were studied with the aid of PANanalytical X'pertPRO diffractometer ( $\mathrm{CuK} \alpha$ radiation: $\lambda=0.1542$ $\mathrm{nm}$ ), with operating conditions at $40 \mathrm{kV}$ and $36 \mathrm{~mA}$. The plot data were obtained from $2 \theta=1-70^{\circ}$ at a scanning rate of $3.350 / \mathrm{min}$.

Table 1: Composite designate and its respective compositions

\begin{tabular}{cc}
$\begin{array}{c}\text { Composite } \\
\text { Designation }\end{array}$ & $\begin{array}{c}\text { Compositions and fibre orientations in the } \\
\text { composites }\end{array}$ \\
\hline $\mathrm{G}_{10} \mathrm{E}$ & $10 \mathrm{wt} \%$ fiber enhancement at $0^{\circ}$ orientation \\
$\mathrm{G}_{20} \mathrm{E}$ & $20 \mathrm{wt} \%$ fiber enhancement at $0^{\circ}$ orientation \\
$\mathrm{G}_{30} \mathrm{E}$ & $30 \mathrm{wt} \%$ fiber enhancement at $0^{\circ}$ orientation \\
$\mathrm{G}_{10} \mathrm{E}_{30}$ & $10 \mathrm{wt} \%$ fiber enhancement at $30^{\circ}$ orientation \\
$\mathrm{G}_{20} \mathrm{E}_{60}$ & $20 \mathrm{wt} \%$ fiber enhancement at $60^{\circ}$ orientation \\
\hline
\end{tabular}

\section{RESULT AND DISCUSSIONS}

Morphological Analysis: The micrographs and EDS of the glass fiber reinforced composite specimens were examined in order to ascertain the elemental composition of the glass fiber after it has been processed. Samples from each composite materials taking into consideration the content of fiber loading and orientation, were studied as shown in the Figure 1.
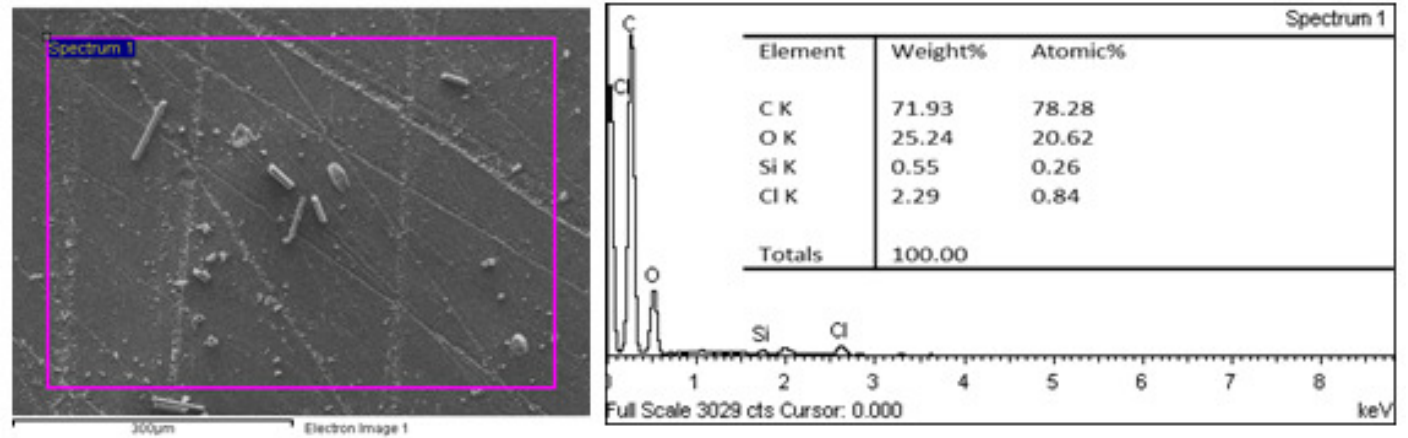

Fig 1: SEM image showing elemental composition of all the five composite specimen.

From Figure 1, it can be observed that the amorphous nature of glass fiber is highly evident in the EDS, as each spectrum virtually represents all the elemental composition as supplied by the manufacturer. Previous works undertaken by other researchers also corroborated these EDS results. Swetha and Kumar 
(2011) studied the elemental composition of glass fiber after incorporating the glass fibre into the matrix (hollow epoxy foams) and the conclusion drawn from the results indicated the retention of all the elemental compositions of the glass fiber. It can also be seen that a fairly good distribution of the glass fiber in the matrix was obtained, as shown in the SEM micrographs. Some of the elemental compositions revealed by EDS are: $\mathrm{C}, \mathrm{O}, \mathrm{Na}, \mathrm{Mg}, \mathrm{Al}, \mathrm{Si}, \mathrm{P}$ and $\mathrm{Ca}$. Part of the deductions from the EDS data is that the orientation and fiber loading of the fiber did not dismember any elemental structure of the composite. Study of the EDS spectra micrograph of the composite specimens, regardless of the fiber orientation, shows that there was
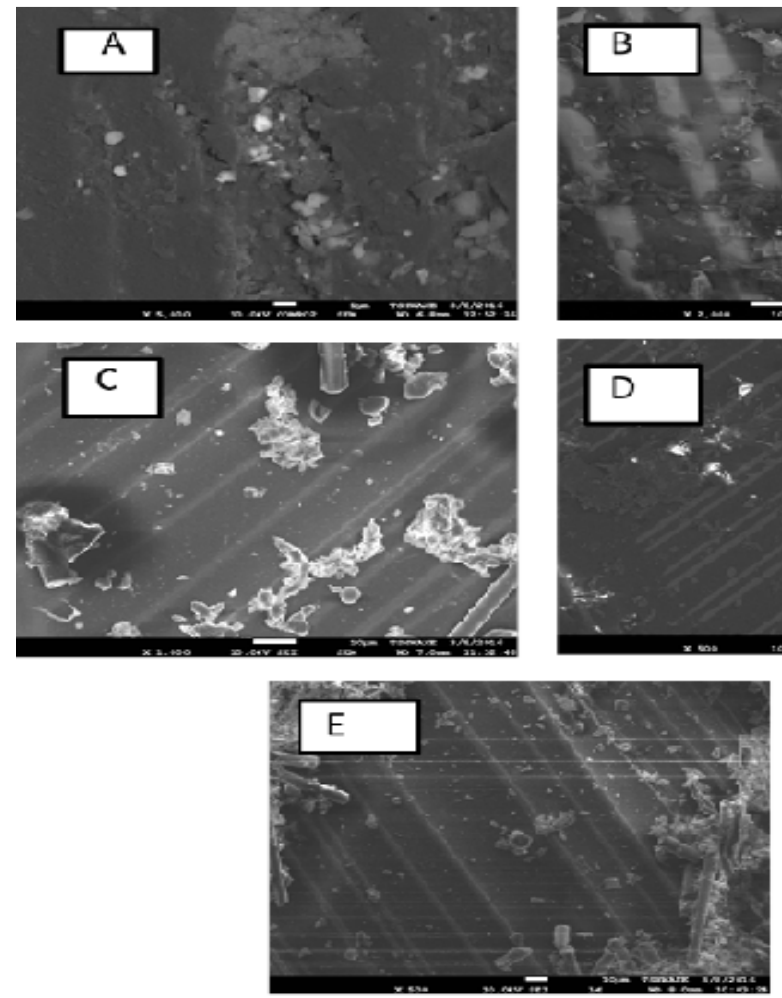

Fig 2: SEM micrograph images of: (A) $\mathrm{G}_{10} \mathrm{E}$, (B) $\mathrm{G}_{20} \mathrm{E}$, (C) $\mathrm{G}_{30} \mathrm{E}$, (D) $\mathrm{G}_{10} \mathrm{E}_{30}$ and (E) $\mathrm{G}_{20} \mathrm{E}_{60}$

It is, therefore, important to discuss some eroded portion of some specimen as revealed by SEM. The SEM micrographs of the $10 \mathrm{wt} \%$ glass fibre reinforced composites at $0^{\circ}$ orientation, $\mathrm{G}_{10} \mathrm{E}$ and composites of $20 \mathrm{wt} \%$ of fibre at $0^{\circ}$ orientation, $\mathrm{G}_{20} \mathrm{E}$, indicate poor fibre matrix adhesion. It can be seen from this particular micrograph that some arrays of broken fiber and some presence of cavities, which indicate the fact that the fibres have been pulled-out from the matrix. Some authors (Ranganna et al. 2012;) have reported that the development of cavities in any composite is an indication of poor interfacial bond between the fiber and the matrix.

Surface morphology of eroded surfaces were studied in order to predict the possible damage potential of any composite materials even after erosion. Hence,
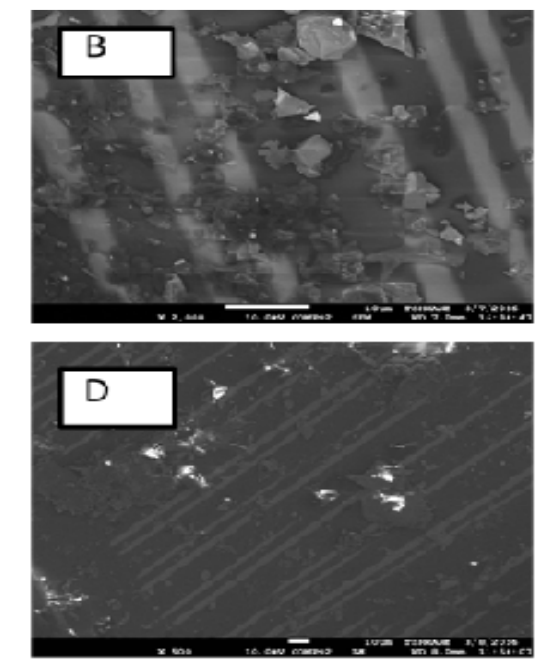

limited or virtually no delamination between the particle and the polymer matrix, which is due to the fairly good interfacial interaction between the reinforcing fiber and the matrix phase. Similar conclusion was observed from the research study reported by Bledzki, Mamun, and Volk (2010).

Surface Morphology of eroded composite specimens:The scanning electron micrograph (SEM) of all the tensile fractured surfaces of the specimens depicted an effective compatibility between the reinforcing fibre and the matrix, as shown in Figure 2 (A-E). very important in composite fabrication in order to ascertain the eroded portion of the reinforcing fibers.

Further analysis of the SEM micrograph of composites $\mathrm{G}_{10} \mathrm{E}_{30}$ and $\mathrm{G}_{20} \mathrm{E}_{60}$ at the impinged angles, clearly shows that there is fiber material pull out as a result of poor interfacial bonding, which may likely lead to micro-ploughing, micro-cutting and ultimately composite deformation. Some authors have also reported that the oriented reinforced composite materials are susceptible to micro-cutting, which may eventually lead to maximum wear at a slight impact. The strength of most the composite material is completely lost when a maximum strain energy is exceeded, leading to the propagation of micro-cracks and exposure of fiber pull-out as largely noticed from 
the micrographs (Figure 2d and e). Similarly, from Figure $2 c$, it was observed that the eroded surface of the composite with 30 wt $\%$ fiber $\left(\mathrm{G}_{30} \mathrm{E}\right)$ loading, shows reasonable micro-cracks on the specimen surface, which may be as a result of inherent brittleness of epoxy resin at $0^{\circ}$ orientation angle. However, it may be predicted that the poor matrix and fibre interface on this composite may culminate into high erosion rate as this poor interface may hinder its application in a refrigerated wall. In the same manner, SEM micrograph of composite with fiber loading $30 \mathrm{wt} \%$ at $0^{\circ}$ orientation $\left(\mathrm{G}_{30} \mathrm{E}\right)$, shows fibers protruded out due to poor interaction between the fibre and the matrix, which is seen in the SEM micrograph in (Figure 2c). Subsequently, these exposed fibers may further disintegrate into small fragments, resulting in excessive erosion wear. These SEM micrographs also show that the dispersion of fibre materials in the resin is more pronounced in unoriented reinforced composite, as with composite with $0^{\circ}$ orientation. Further analysis of successive fibre loading, i.e., between 10 to $30 \mathrm{wt} \%$ fiber loading, showed a rubbing action on the adhesion face of the specimen as shown in their respective micrographs. Increasing fiber orientation from $30^{\circ}$ to $60^{\circ}$, showed that the erosion rate was further deepened as shown.

$X$-ray diffraction studies: The orientation and loading of glass fibres in the epoxy resin and the identification of peaks of reinforced glass fiber and its characteristics in the matrix were further studied using $\mathrm{x}$-ray diffraction analysis, as shown in Figure 3.

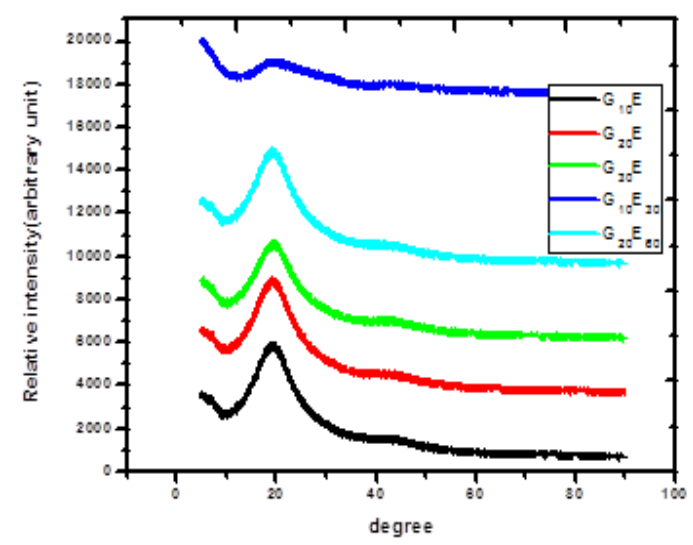

Fig 3: XRD patterns of: $G_{10} E, G_{20} E, G_{30} E, G_{10} E_{30}$ and $G_{20} E_{60}$ respectively shows that the composites are predominantly amorphous in nature

X-ray diffractogram of oriented glass fiber were represented by the majority of elements, silica which is a confirmatory of directional loading in the epoxy resin. Figure 3 also showed that the XRD of $\mathrm{G}_{10} \mathrm{E}$, $\mathrm{G}_{20} \mathrm{E}, \mathrm{G}_{30} \mathrm{E}, \mathrm{G}_{10} \mathrm{E}_{30}$ and $\mathrm{G}_{20} \mathrm{E}_{60}$ indicated a peak at Bragg's angle $2 \theta=20.6^{\circ}$, affirming the remnant crystalline silica in the composite. It can be seen that the glass fiber and epoxy resin do not have any other identifiable XRD peaks and this indicates that the materials were amorphous in nature. This unidentifiable peak appears to have cut across all the composites developed, regardless of fiber loading and orientation. It is also important at this junction to reiterate on past literatures in this particular area, which affirmed the amorphous nature of glass fiber. Kanny and Mohan (2014) also reported similar results in XRD peak of epoxy resin filled with 3 wt.\% nanoclay which resulted in no distinct XRD peaks. The authors reported on the XRD analysis of glass fibre and concluded that the dispersion of glass fibre may have been uniformly distributed in the matrix, which resulted in no specific peak. The research reported by Hao et al. (2011) also corroborated this finding, especially in the interpretation of XRD data. The finding of their experimental works showed that the XRD analysis of fine glass did not produce any peak, which is in line with other reported works (Felix Antonio et al. 2012); Quaresimin, Salviato, and Zappalorto (2012); (Tjong 2006). It can also be seen in this work that the absence of peak is as a result of the uniform distribution of glass fibre in the matrix phase. Conclusions: It has been noted in this work that the newly introduced Ampreg 21epoxy resin may be considered as an excellent materials suitable for hand lay-up composite preparations. The substantial improvement in the interfacial adhesion between the matrix and the fibers as revealed by SEM is an indication of successful composite development.

Acknowledgements: The lead author wishes to thank Tshwane University of Technology, South Africa for providing the platform to conduct this research work. The lead author equally appreciates the home institution (Olabisi Onabanjo University, Nigeria) for funding this project.

\section{REFERENCES}

Abdellaoui, H; Hala, B; Jamal, E; Rachid, B; Abouelkacem, Q (2015). Fabrication, characterization and modelling of laminated composites based on woven jute fibres reinforced epoxy resin, Mat. Design, 68: 104-13.

Allred, RE; Sheldon, PW; Shin, EE; Linda, I; Linda, M; Demetrios, P; Donald, W; James, KS (2003). The influence of sizings on the durability of hightemperature polymer composites, High Performance Polymers, 15: 395-419.

Biswas, S; Basu, D; Amar, P; Alok, S (2011). Effect of fiber loading and orientation on mechanical and erosion wear behaviors of glass-epoxy composites, Polymer composites, 32: 665-74.

Bledzki, AK; Abdullah, AM; Jürgen, V (2010). Physical, chemical and surface properties of wheat husk, rye husk and soft wood and their polypropylene composites, Composites Part A: Appl. Sci. Manufacturing, 41: 480-88. 
Devaux, E; Caze, C (2000). Evolution of the interfacial stress transfer ability between a glass fibre and a polypropylene matrix during polymer crystallization, Journal of adhesion science and technology, 14: 965-74.

Dong, W; Heng-Chang, L; Soo-Jin, P; Fan-Long, J (2014). Fracture toughness improvement of epoxy resins with short carbon fibers, J. Indust. Engineer. Chem. 20: 1220-22.

Etcheverry, M; Silvia, EB (2012). Glass fiber reinforced polypropylene mechanical properties enhancement by adhesion improvement, Materials, 5: 1084-113.

Fara, S; Pavan, A (2004). Fibre orientation effects on the fracture of short fibre polymer composites: on the existence of a critical fibre orientation on varying internal material variables, J. Mat. Sci. 39: 3619-3628.

Felix, A; López, MMI; García-Díaz, I; Rodríguez, O; Alguacil, FJ; Romero, M (2012). Recycling of glass fibers from fiberglass polyester waste composite for the manufacture of glass-ceramic materials, J. Environ. Protect. 3(8): 740-747.

Hao, Y; Fuchun, L; Hongwei, S; Enhou, H; Zhenyu, $\mathrm{W}$ (2011). The influence of ultra-fine glass fibers on the mechanical and anticorrosion properties of epoxy coatings, Progress in Organic Coatings, 71: 188-97.

Kanny, K; Mohan,TP (2014). Resin infusion analysis of nanoclay filled glass fiber laminates, Composites Part B: Engineering, 58: 328-34.

Kenane, M; Benmedak=hene, S; Azari, Z (2010). Fracture and fatigue study of unidirectional glass/epoxy laminate under different mode of loading, Fatigue and Fracture of Engineering Materials and Structures, 33: 284-93.

Miller, SG, Jonathan, LB; Michael JM; Paula JH; Jeremy, PB; Jan-Michael, G; Ronald, EA (2010). Characterization of epoxy functionalized graphite nanoparticles and the physical properties of epoxy matrix nanocomposites, Composites Sci. Technol. 70: $1120-25$.
Natarajan, K; Padma, CB (2014). Study of mechanical and morphological properties of glass fiber reinforced modified epoxy composites. International Journal of Research in Engineering and Technology, 3(1): 1-6.

Norman, DA; Richard ER (2003). The effect of fiber orientation on the toughening of short fiberreinforced polymers, Journal of applied polymer science, 90: 2740-51.

Quaresimin, M; Marco, S; Michele, Z (2012). Fracture and interlaminar properties of clay-modified epoxies and their glass reinforced laminates, Engineering Fracture Mechanics, 81: 80-93.

Rahman, AS; Vijaya, R; Shaik, J (2015). Thermal and mechanical properties of woven glass fiber reinforced epoxy composites with carbon nanotubes grown in-situ, The International Journal of Engineering and Science, 4(12):54-61.

Rahman, NA; Aziz, H; Yahya, R; Lafia-Araga, RA (2013). Impact properties of glassfiber/polypropylene composites: The influence of fiber loading, specimen geometry and test temperature, Fibers and Polymers, 14: 18771885.

Ranganna, H; Karthikeyan, N; Nikhilmurthy, V; Raj Kumar, S; Ashok Kumar, M; Ramachandra Reddy, G (2012). Mechanical and thermal properties of epoxy based hybrid composites reinforced with sisal/glass fibres. ISSN.22777156.

Swetha, C; Ravi, K (2011). Quasi-static uni-axial compression behaviour of hollow glass microspheres/epoxy based syntactic foams. Mat. Design. 32: 4152-63.

Thomason, JL; Yang, L (2014). Temperature dependence of the interfacial shear strength in glass-fibre epoxy composites, Composites Sci. Technol. 96: 7-12.

Tjong, SC (2006). Structural and mechanical properties of polymer nanocomposites, Mat. Sci. Engineer. Reports. 53: 73-197.

Zhao, Z; Xu, C; Xin, W (2015). Deformation behavior of woven glass/epoxy composite substrate under thermo-mechanical loading, Mat. Design. 82: 130-35. 